\title{
Biomarkers of Hepato-renal Damage of Fuel Filling Station Attendants Using or Abstaining from Use of Protective Gears
}

\author{
Ayobola A Iyanda ${ }^{1 *}$, John I. Anetor ${ }^{2}$
}

\begin{abstract}
Affiliations:
${ }^{1}$ Department of Chemical Pathology, College of Health Sciences, Ladoke Akintola University of Technology, Osogbo, Nigeria.

${ }^{2}$ Department of Chemical Pathology, College of Medicine, University of Ibadan, Ibadan, Nigeria.
\end{abstract}

\section{Correspondence to:}

Ayobola A Iyanda

Department of Chemical Pathology, College of Health Sciences, Ladoke Akintola University of Technology, Osogbo, Nigeria.

Email: lapeiyanda@yahoo.com

\section{How to cite this Article:}

Ayobola A Iyanda, John I. Anetor. Biomarkers of hepato-renal damage of fuel filling station attendants using or abstaining from use of protective gears . Ann. Clin. Chem. Lab. Med. 2017:3(1);15-21

DOI: : http://dx.doi.org/10.3126/acclm.v3i1.17176

(C) 2017 Nepalese Association for Clinical Chemistry

\begin{abstract}
BACKGROUND

Different gears (e.g. overall, mask, gloves) are being used for protective purposes by fuel filling station attendants (FFSA) in Nigeria. Whether they can adequately protect susceptible organs like liver and kidney remains largely undetermined. The aim of the study is to compare the biochemical parameters of hepato-renal axis in FFSA that abstained from and that used protective gears in the course of daily duty.
\end{abstract}

\section{METHODS}

The study population was grouped into three; GROUP A was made up of ten adult male FFSA who have used the protective measures consistently in the course of dispensing petroleum products. GROUP B was composed of 40 FFSA who did not use protective gears. GROUP C was the control group made up of thirty male adults not exposed to petroleum products. The minimum period of exposure for FFSA recruited for the study was 5 years. Information on worker safety was obtained through administered questionnaire concerning the use of self-protective equipment as a routine safety protocol for personal protection. Serum was utilized to assess biochemical indices of hepato-renal functions. Statistical differences were determined using Student's t test and analysis of variance. $\mathrm{p}<0.05$ was considered significant.

\section{RESULTS}

Both GROUP A and GROUP B showed activities or levels of ALP, AST, ALT, creatinine, urea, albumin, and total protein that were significantly different compared with control (GROUP C), suggestive of hepatic damage.

\section{CONCLUSION}

Data obtained from this study suggest that the three available protective gears used by FFSA in GROUP B did not significantly reduce exposure.

KEY WORDS: kidney, liver, petroleum product exposure 


\section{NTRODUCTION}

Prolonged close proximity to service station (where fuel attendants work) is a significant source of exposure to harmful chemicals ${ }^{1}$ and this is not limited to any part of the world, although it may be more common in nations that do not have or enforce laws against exposure to toxic substances in the workplace. According to a study conducted in Italy in 1997, in which environmental benzene levels in twenty-six petrol stations were measured using both active and passive stationary and personal samplers. Brugnone et al. ${ }^{2}$ reported that there was remarkable level of benzene in the environment, although it seems that seasonal changes affected degree of environmental contamination since levels were significantly lower in winter and higher in summer.

Aside the measurement of environmental benzene levels, when blood benzene levels were measured by Brugnone and colleagues ${ }^{2}$ in the petrol station operators at the end of the work shift and the following morning before work commenced. The overall mean blood levels of benzene in these petrol station operators at the end of the work shift were greatly elevated (the levels though were significantly lower in winter and higher in summer). The elevations persisted till the following morning, although lower than those found at the end of the work shift, but still significantly higher than the mean blood benzene levels of control subjects. This indicates that exposure to benzene is a form of occupational hazard for this studied population.

Nowadays many developed nations have more or better safety measures in place against toxic exposure than what prevailed in 1997, but there are many developing countries that similar degree of toxic exposure reported by Brugnone et al. ${ }^{2}$ still prevails. Nganje et al. ${ }^{3}$ reported high concentrations of polycyclic aromatic hydrocarbons (PAHs) in surface soils from petroleum handling facilities (e.g. kerosene tank, generating plant, petrol stations, mechanic workshops) located within Calabar metropolis (Nigeria). In addition, as recent as 2015, Kamal et al. ${ }^{4}$ reported of increasing
PAH exposure in automobile mechanic workstation in Pakistan. In Thailand the mean benzene, ethylbenzene, toluene, and xylene (BTEX) concentration in gas stations was slightly higher than that of the roadside. All these reports support the hypothesis that exposure to components of petroleum products is a common occupational hazard in petrol attendants and the use of protective gears may limit the degree of exposure. The aim of the study is to investigate the impact of the some protective gears on markers of hepatic and renal damage in serum of FFSA.

\section{METHODS}

The study consisted of three groups; the first group (GROUP A) was made up of ten adult male fuel filling station attendants (FFSA) who have used the protective measures (face mask, overall, gloves) consistently in the course of their duty while dispensing petroleum products. The second group (GROUP B) was composed of 40 adult male FFSA who did not use protective gears. Thirty male adults served as the control (GROUP C). All participants in the study were within the age group of twenty-one to twenty-nine years. The minimum period of exposure for FFSA recruited for the study was 5 years; participants were based in Ibadan metropolis and its environs. Random sampling technique was used to determine which fuel filling station to be incorporated in the study. In addition, the same technique was adopted to identify the participants in all stations that would be involved in the study except the FFSA in the first set i.e. GROUP A.

After having clearly describing the purpose of the study and expected outcomes, informed consent of each subject was obtained. The thirty apparently healthy male adults that were selected from the general population that served as the control, confirmed that they had not been involved in any occupation linked with exposure to gasoline/diesel either as automobile mechanics, fuel filling station attendants, commercial car drivers or motorcycle riders, or any other occupation (common in the environment) capable of 
causing exposure to petroleum products. Exclusion criteria included the following: lifestyle choices capable of modulating the hepato-renal indices, presence of hepato-renal diseases; under-aged FFSA, female FFSA, and male FFSA with exposure period less than 5 years. Any male FFSA that met the inclusion criteria but was moonlighting in other occupations related to gasoline which were capable of causing additional exposure were excluded from the study. Worker safety was assessed by observing and obtaining information through administered questionnaire on the use of selfprotective equipment like overall, gloves, masks, etc. as a routine safety protocol for personal protection. Duration of exposure at the present employment or past ones (related to fuel exposure) was also obtained.

All samples were taken at or towards the end of 8 hour working shift. $5 \mathrm{~mL}$ of blood was taken from the ante-cubital vein of each subject and were immediately transferred into tubes that were anticoagulant free. Each blood sample was centrifuged at $2500 \mathrm{~g}$ to obtain serum which was immediately kept frozen at $-20^{\circ} \mathrm{C}$ until required for analysis of renal and hepatic parameters. All procedures were carried out in accordance with revised Helsinki Declaration. Total bilirubin, total protein and albumin were estimated in the sera of fuel filling station attendants and control subjects by the method of Jendrassik-Groff ${ }^{5}$, Biuret method ${ }^{6}$, and standard Bromocrescol green method respectively. While the level of creatinine was determined by Jaffé reaction, that of urea was assessed by the diacetyl monoxime method. Both uric acid level as well as serum activities of hepatic enzymes were also estimated. The enzymes included alanine aminotransferase, aspartate aminotransferase, alkaline phosphatase and $\gamma$-glutamyl transferase (ALT, AST, ALP \& $\gamma$-GT). The activities of AST \& ALT were estimated by employing the method of Bergmeyer et al. ${ }^{7}$ but that of alkaline phosphatase (ALP) was by the method of Mc Comb and Bowers ${ }^{8}$. Hitachi ${ }^{\circledR} 902$ automated machines (Roche Diagnostic, Germany) was used for these estimations.

Data obtained were subjected to statistical analysis using SPSS version 15 to obtain mean \pm SD (standard deviation). Student's t- test

Table 1: Serum levels or activities of markers of hepatic and renal damage of fuel filling station attendants and control subjects.

\begin{tabular}{|c|c|c|c|c|c|}
\hline Parameter & GROUP A & GROUP B & GROUP C & F-value & P-value \\
\hline $\begin{array}{l}\text { Gamma-glutamyl trans- } \\
\text { ferase (IU/L) }\end{array}$ & $45.02 \pm 5.11$ & $44.60 \pm 6.62$ & $42.86 \pm 6.09$ & 0.036 & 0.842 \\
\hline $\begin{array}{l}\text { Alkaline phosphatase (IU/ } \\
\text { L) }\end{array}$ & $71.33 \pm 6.05^{*}$ & $74.93 \pm 9.04 \ddagger$ & $60.00 \pm 15.67$ & 12.106 & 0.0389 \\
\hline Total protein (g/L) & $74.99 \pm 8.23 *$ & $75.86 \pm 5.98 \ddagger$ & $79.94 \pm 13.75$ & 31.307 & 0.0149 \\
\hline Albumin (g/L) & $33.12 \pm 9.48^{*}$ & $30.45 \pm 3.03 \ddagger$ & $38.31 \pm 4.66$ & 4.407 & 0.0299 \\
\hline §Globulin (g/L) & $41.87 \pm 5.22$ & $45.41 \pm 3.66 \ddagger$ & $41.63 \pm 7.50$ & 1.904 & 0.3619 \\
\hline$\S$ Total bilirubin ( $\mu \mathrm{mol} \backslash \mathrm{L})$ & $13.50 \pm 0.96$ & $18.40 \pm 1.98 \ddagger$ & $13.12 \pm 1.97$ & 3.106 & 0.0119 \\
\hline $\begin{array}{l}\text { Alanine aminotransferase } \\
(\mathrm{IU} / \mathrm{L})\end{array}$ & $34.91 \pm 4.30^{*}$ & $35.39 \pm 4.20 \ddagger$ & $27.13 \pm 2.64$ & 6.183 & $0.008 \rrbracket$ \\
\hline $\begin{array}{l}\text { Aspartate aminotrans- } \\
\text { ferase (IU/L) }\end{array}$ & $39.91 \pm 4.72 *$ & $39.90 \pm 5.51 \ddagger$ & $33.26 \pm 8.03$ & 9.772 & 0.0229 \\
\hline §Uric acid (mmol \L) & $150.35 \pm 22.84^{*}$ & $179.82 \pm 19.85 \ddagger$ & $162.92 \pm 15.40$ & 3.843 & 0.0279 \\
\hline Creatinine $(\mu \mathrm{mol} \backslash \mathrm{L})$ & $27.38 \pm 2.95^{*}$ & $28.11 \pm 4.59 \ddagger$ & $22.06 \pm 3.03$ & 48.324 & 0.0059 \\
\hline Urea (mg/dL) & $27.64 \pm 3.41 *$ & $29.75 \pm 2.83 \ddagger$ & $20.91 \pm 3.36$ & 43.803 & 0.0099 \\
\hline
\end{tabular}

Abbreviations: GROUP A- fuel filling station attendants that did not use protective gears; GROUP B- fuel filling station attendants that rarely used protective gears; GROUP C- control. Results are expressed as mean \pm standard deviation. ${ }^{*} \mathrm{P} \leq 0.05$ is significant when Group A and GROUP C were compared. $\$ \mathrm{P} \leq 0.05$ is significant when Group B and GROUP C were compared. $\S \mathrm{P} \leq 0.05$ is significant when Group A and GROUP B were compared. $\mathrm{P} \leq 0.05$ is significant when the three groups were considered. 
was used to establish the extent of significant difference between GROUP A and GROUP C; GROUP B and GROUP C; as well as GROUP $A$ and GROUP B. The results of all the three groups were analyzed using analysis of variance. $\mathrm{P} \leq 0.05$ was considered significant.

\section{RESULTS}

The results of the estimated biochemical markers are presented in Table 1 below. While the activities of $\gamma$ - glutamyl transferase, and concentrations of globulin and total bilirubin were not significantly different when GROUPS $\mathrm{A}$ and $\mathrm{C}$ were compared $(\mathrm{p}>0.05)$, creatinine, urea, ALP, AST, ALT were significantly higher $(p<0.05)$ whereas total protein, albumin, and uric acid were significantly lower $(p<0.05)$ in GROUP A attendants compared with control. On the other hand, although $\gamma$-glutamyl transferase was not significantly different $(\mathrm{p}>0.05)$ when GROUP $\mathrm{B}$ and GROUP C were compared ALP, AST, ALT, creatinine, urea, uric acid and globulin were significantly higher $(p<0.05)$ in GROUP B attendants than GROUP C (control) but total protein and albumin were lower $(\mathrm{p}<0.05)$. Comparison of GROUP A and GROUP B revealed significant differences only in the levels of total bilirubin, globulin and uric acid. Using ANOVA, inter-group comparison of GROUPS A, B, and $\mathrm{C}$ showed significant difference for all parameters except $\gamma$-glutamyl transferase.

All of fuel filling station attendants in GROUP $B$ revealed that they had not used all of the safety measures together at the same time. All attendants in GROUP B indicated that of all the three safety measures (face mask, overall, gloves), both face mask and gloves were never used at anytime, while 5 attendants reported that in the 5 years preceding the study period, overall was used on very rare occasions e.g. during the cold harmattan session. Thirty-five of the attendants in GROUP B did not think face mask could be of assistance in limiting gasoline exposure to them. All the FFSA in GROUP $A$ on the other hand indicated consistent use of the protective gears while in the fuel station environment.
According to ACGIH ${ }^{9}$ and US EPA 10 components of gasoline- benzene, toluene, ethylbenzene and xylene (BTEX) are volatile organic compounds and benzene and ethyl-benzene are well known carcinogens. The present study has demonstrated the hepato and nephrotoxic effects of gasoline exposure in FFSA in both GROUP A

and GROUP B. According to ATSDR [11] and a few other studies in the past, benzene also affects hematopoietic system, the central nervous system and the reproductive system. While toluene affects the reproductive and the central nervous systems, ethylbenzene and xylene can have respiratory and neurological effects ${ }^{12-14}$

However, the study of Tunsaringkarn et al. ${ }^{15}$ seems to differ since the non-carcinogenic risk of exposure to BTEX compounds, were lower than the reference hazard lev-el for both gasoline station and the roadside which would suggest no adverse health effects to the bone marrow, as well as both hematological and neurological parameters. The hepato-nephron toxic effects.

observed in the present test subjects (FFSA) cannot be ascribed to toluene, while toluene is more rapidly absorbed, soluble in the blood with a half life 15-20 hours; and has chronic effect on some organs it does not harm the liver, lungs, kidneys and heart ${ }^{13,16}$. Yet the synergy between toluene and benzene reported by Kitwattanavong et al. ${ }^{17}$ cannot be ruled out as being the basis of significantly higher levels of markers of both liver and kidney of the fuel filling station attendants.

In many parts of world, and as it has also been observed in Thailand by Tunsaringkarn et al. ${ }^{15}$, gasoline station workers are directly exposed to BTEX compounds not only through the nasal and oral routes but also by dermal route as well. However, the main route of ex-posure is the respiratory system. The situation in Nigeria is further compounded by incessant petroleum product scarcity which usually results in the sale of gasoline and other products in jerry-cans and other containers, a

\section{DISCUSSION}


sale process that has widely been recognized to be accompanied by splashing of these products not only on humans but also in fuel filling station environment. Splashing will undoubtedly make both dermal and oral routes more prominent and possible sources of exposure. The liver is usually the most susceptible organ to chemical insult, it rapidly and extensively remove chemicals thereby greatly decreasing the quantity of drug reaching the general circulation. Since it is the first organ that comes in contact with a drug or chemical after absorption from the gastrointestinal tract or peritoneal space, this translates to the fact that the liver is confronted with highest concentrations of potential toxicants.

More importantly the high susceptibility of the hepatic cells to chemical attack can also be linked to the fact that it is the primary organ for the biotransformation of many agents within the body. The metabolic transformation process is mostly known for altering the chemical in such a manner that it becomes biologically inactive within the body as well as becomes more polar and water-soluble which invariably makes these agents more easily excreted from the body. This makes the liver a detoxification organ, since it not only depresses the biological activity of a toxic chemical but lowers its blood levels as well, thereby preventing accumulation of an agent to its toxic levels within the body. Unfortunately there are disadvantages that may result from these important roles, being the main organ metabolizing chemicals, toxic reactive chemicals or short-lived intermediates that are formed during the biotransformation process will have grave impact on hepatic cells.

The liver consists of several types of cells and exposure to chemical agents affects the integrity of the cells in diverse ways. The hepatocytes or parenchymal cells, that make up about three fourth of the total cells in the human liver are relatively large cells and make up the major section of the hepatic lobule. As a result of this large numbers as well as their extensive xenobiotic metabolizing activity, these cells are more greatly and adversely affected by hepato-toxic chemicals. Another cell type, the endothelial cells that line the sinusoid are much smaller than hepatocytes but numerous, and constitute majority of the remaining cells in the liver. In addition, the hepatic microvasculature also contains fixed macrophages that are also known as the Kupffer cells. They phagocytize microorganisms and foreign particulates in the blood and their role as immune components may be the basis of hepato toxicity linked immune response. These cells are also capable of releasing reactive oxygen species and cytokines, and studies have revealed that they play an important role in inflammatory responses in the liver. The liver is also known to contain fat-storing cells, parasinusoidal cells, or stellate cells, which can be found between parenchymal and endothelial cells and their role in chemical-induced liver injury has not been extensively defined as those of parenchymal cells. While histology reports are not available to confirm the contribution of each cell type, the significant increases in the activities of aspartate and alanine aminotransferase, and alkaline phosphatase in both GROUPS A \& B suggest hepatocytes membrane damage with possible cholestasis. Low levels of albumin (in both GROUP A and B) than control suggest that the toxic effects of gasoline exposure altered the synthetic ability of the liver whereas the significantly higher level of globulin in GROUP B is an indication of inflammatory response, especially as albumin was also decreased. The non-significant difference in level of globulin in GROUP B indicates that they were not prone to infection.

All renal markers were also significantly increased suggesting renal damage. This is not unexpected, while it is not all hepatotoxic agents that are equally nephrotoxic, when the toxicity of an agent is mediated via free radical action and the enzymes responsible for the generation of the reactive oxygen species is expressed sufficiently in both liver and kidney then hepato-nephrotoxic effects may be the consequence of toxic exposure. Furthermore, in this category of test subjects, where gasoline, diesel, and kerosene that they are exposed to are made up of several individual 
toxic chemicals, the involvement of both hepatic and renal cells may not be unexpected.

The liver has high regenerative potential and the possibility of many of the hepatic markers reverting to control level cannot be ruled out. Therefore there is need to carry out further studies, to investigate hepato-renal markers among those who are permanently in filling station (current attendants) and comparing them with those who have abstained from exposure (former fuel filling station attendants) to see if these dangerous effects are reversible. There is no doubt that different ways of bringing about reduction in exposure levels of the constituents of gasoline (the most volatile and the most widely sold of the petroleum products) are beneficial and should reasonably be the first line of action in preventing this occupational hazard.

The fact that the results showed that many of the markers of hepato-renal function of not only GROUP B but those of GROUP A were significantly different were compared individually with GROUP C (control), may be an indication that the three protective measures (overall, glove, face mask) did not prevent hepatic and renal damage. This suggests that the use of overall, face mask, and gloves may not eliminate contact with petroleum products completely. Whether this is peculiar to Nigeria, a nation where persistent scarcity of petroleum product usually results in commotion with accompanying spillage/splashing of the products (not only on human subjects but filling station environment) has not been determined. In addition, the highly volatile nature of petrol, the most commonly dispensed of all petroleum products in many filling stations in Nigeria may transverse the protective effects of these gears, leading to increased contact.

\section{CONCLUSION}

The comparable levels or activities of many of the markers of hepatic and renal functions in GROUP A and GROUP B subjects, suggest that these measures did not have any significant effect in protecting against hepato-renal damage. This implies that these common protective gears are not sufficient to deter damage to organs. Therefore alternative means of protection needed to be devised for these attendants.

\section{REFERENCES}

1. Carrieri M, Bonfiglio E, Scapellato ML, Maccà I, Tranfo G, Faranda P, Paci E, Bartolucci GB. Comparison of exposure assessment methods in occupational exposure to benzene in gasoline filling -station attendants. Toxicology Letters 2006;162 (2-3):146-52.

2. Brugnone F, Perbellini L, Romeo L, Cerpelloni M, Cecco A, Leopard Barra E, Moro G, Marchiori L, Ferracin A. Environmental exposure and blood levels of benzene in gas station attendants. Comparison with the general population. La Medicina del L a voro $1997 ; 88$ ( 2$): 131-47$.

3. Nganje TN, Edet AE, Ekwere SJ. Distribution of PAHs in surface soils from petroleum handling facilities in Calabar. Environmental Monitoring Assessment 2007;130(1-3):27-34

4.

Kamal A, Cincinelli A, Martellini T, Palchetti I, Bettazzi F, Malik RN. Health and carcinogenic risk evaluation for cohorts exposed to PAHs in petrochemical workplaces in Rawalpindi city (Pakistan). International Journal Environmental Health Research. 2015; 5:1-21.

5. Koch TR, Doumas BT. Bilirubin, total and conjugated, modified Jendrassik- Grof method. Am Ass Clin Chem. $1982 ; 113$.

6. Kingsley CR. The direct biuret method for determination of serum proteins. J Lab Clin Med. 1942; 27: 840-845.

7. Bergmeyer HU, Scheibe P, Wahlefeld AW. Optimization of methods for aspartate and alanine amino transferase. Clin Chem. 1978; 24:58-73.

8. McComb RB, Bowers GN, Jr. A study of optimum buffer conditions for measuring alkaline phosphatase activity in human serum. Am Ass Clin Chem. 1972; 18: 97.

9. ACGIH. TLVs and BEIs. Based on the documenta $\neg$ tion of the threshold limit values for chemical sub $\neg$ stances and physical agents \& biological exposure indices. Cincinnati, OH, USA, 2010:1329.

10. US EPA. Integrated Risk Information System (IRIS) on Benzene. National Center for Environmental Assessment, Office of Research and Development, Washington DC, 2002.

11. ATSDR. Toxicological Profile for benzene. (Draft for Public Comment). Atlanta, GA, USA, 2005.

12. US EPA. Toxicological review of xylene: In support of summary information on Integrated risk information system (IRIS). 2003, Available from www. epa.gov/iris (Accessed October 20, 2011). 
13. US EPA. Toxicological review of toluene: In support of summary information on Integrated risk information system (IRIS). 2005, Available from www. epa.gov/iris (Accessed October 15, 2011).

14. ATSDR. Toxicological profile for ethylbenzene. Atlanta, GA, USA, 2010.

15. Tunsaringkarn T, Siriwong W, Rungsiyothin A, Nopparatbundit S. Occupational Exposure of Gasoline Station Workers to BTEX Compounds in Bangkok, Thailand. The International Journal of Occupational and Environmental Medicine 2012;3:117-25.

16. Satake M, Mido Y, Sethi SE, et al. Petroleum and solvents In: Environmental Toxicology. Publish by Discovery Publishing house, Darya Ganji, New Delhi 110 002, India 2001: 52-81.

17. Kitwattanavong M, Prueksasit T, Morknoy D, Inhalation exposure to carbonyl compounds and BTEX and health risk assessment of gas station workers in the inner city of Bangkok. Proceedings of the 42nd Asiapacific Academic Consortium for Public Health (APACPH) Conference on Strength $\neg$ ening Public Health Institutions to Address Non Communicable Diseases and Emerging Health Challenges, 24-27 November 2010, Bali, Indone $\neg$ sia: 87-8. 